\title{
Influence of deprivation on initial severity and prognosis of patients admitted to the ICU: the prospective, multicentre, observational IVOIRE cohort study
}

Jean-Pierre Quenot ${ }^{1,2,3,4^{*}}$ (D) Julie Helms ${ }^{5,6}$, Guylaine Labro ${ }^{7}$, Auguste Dargent ${ }^{1,2,3}$, Nicolas Meunier-Beillard ${ }^{4,8}$, Elea Ksiazek ${ }^{4,8}$, Pierre-Edouard Bollaert ${ }^{9}$, Guillaume Louis ${ }^{10}$, Audrey Large ${ }^{1}$, Pascal Andreu ${ }^{1}$, Christophe Bein ${ }^{11}$, Jean-Philippe Rigaud ${ }^{12}$, Pierre Perez ${ }^{13}$, Raphaël Clere-Jeh1 ${ }^{5,6}$, Hamid Merdji ${ }^{5,6}$, Hervé Devilliers ${ }^{4,14}$, Christine Binquet ${ }^{4}$, Ferhat Meziani ${ }^{5,6,15}$, Isabelle Fournel ${ }^{4}$ and the IVOIRE Trial Investigators and the CRICS TRIGGERSEP Group (Clinical Research in Intensive Care and Sepsis Trial Group for Global Evaluation and Research in Sepsis)

\begin{abstract}
Background: The influence of socioeconomic status on patient outcomes is unclear. We assessed the impact of socioeconomic deprivation on severity of illness at intensive care unit (ICU) admission, and on the risk of death at 3 months after ICU admission.

Methods: The IVOIRE study was a prospective, observational, multicentre cohort study in the ICU of 8 participating hospitals in France, including patients aged $\geq 18$ years admitted to the ICU and receiving at least one life support therapy for organ failure. The primary outcomes were severity at admission (assessed by SAPSII score), and mortality at 3 months. Socioeconomic data were obtained from interviews with patients or family. Deprivation was assessed using the EPICES score.
\end{abstract}

Results: Among 1294 patents included between 2013 and 2016, 629 (48.6\%) were classed as deprived and differed significantly from non-deprived subjects in terms of sociodemographic characteristics and pre-existing conditions. The mean SAPS II score at admission was $50.1 \pm 19.4$ in deprived patients and $52.3 \pm 17.3$ in non-deprived patients, with no significant difference by multivariable analysis $(\beta=-1.85[95 \% \mathrm{Cl}-3.86 ;+0.16, p=0.072])$. The proportion of death was $31.1 \%$ at 3 months, without significant differences between deprived and non-deprived patients, even after adjustment for confounders.

Conclusions: Deprivation is frequent in patients admitted to the ICU and is not associated with disease severity at admission, or with mortality at 3 months between deprived and non-deprived patients.

Trial registration The IVOIRE cohort is registered with ClinicalTrials.gov under the identifier NCT01907581, registration date 17/7/2013

Keywords: Socioeconomic, Deprivation, Critically ill, Intensive care unit

\footnotetext{
*Correspondence: jean-pierre.quenot@chu-dijon.fr

1 Service de Médecine Intensive-Réanimation, CHU Dijon Bourgogne, 14

rue Paul Gaffarel, B.P 77908, 21079 Dijon Cedex, France

Full list of author information is available at the end of the article
}

\section{Springer Open}

(c) The Author(s) 2020. This article is licensed under a Creative Commons Attribution 4.0 International License, which permits use, sharing, adaptation, distribution and reproduction in any medium or format, as long as you give appropriate credit to the original author(s) and the source, provide a link to the Creative Commons licence, and indicate if changes were made. The images or other third party material in this article are included in the article's Creative Commons licence, unless indicated otherwise in a credit line to the material. If material is not included in the article's Creative Commons licence and your intended use is not permitted by statutory regulation or exceeds the permitted use, you will need to obtain permission directly from the copyright holder. To view a copy of this licence, visit http://creativeco mmons.org/licenses/by/4.0/. 


\section{Background}

Despite the outstanding progress achieved in critical care in recent years, mortality remains high among patients admitted to the intensive care unit (ICU) [1, 2]. Mortality in ICU patients reflects the severity of the disease justifying the ICU admission, which is often assessed using scores such as the SAPS II, APACHE II or SOFA [3-5]. However, although these scores are relevant to compare the profiles of patients across ICUs, or as adjustment variables in clinical trials, they are no longer the only parameters that should be taken into account to explain mortality in the ICU. While the severity of disease leading to admission naturally accounts for a large part in explaining mortality, other aspects also need to be taken into consideration.

Socioeconomic status, psychosocial, material and behavioural factors are among the many parameters that contribute to inequalities in healthcare. These factors can compound pre-existing vulnerability, or render vulnerable patients who are already weakened by underlying illness [6-8]. The impact of health inequalities was investigated in a large study in 22 countries across all parts of Europe, based on hospital admission registers. The authors reported that the rates of death were significantly higher in groups with lower socioeconomic status, as assessed by level of education, occupational class and income [9]. They also found that substantial inequalities in health existed between higher and lower socioeconomic groups, although the magnitude of the difference varied across countries [9]. These findings have also been confirmed in other specific clinical contexts, such as trauma, cardiovascular disease and cancer [10-14].

In the field of critical care, a number of studies have investigated the influence of socioeconomic status on patient outcomes [15-20]. However, they have all been the object of some criticism, notably because they were single-centre, used retrospective or medical informatics data, had short follow-up (up to ICU or hospital discharge only), analysed subgroups only, or because other factors influencing the prognosis of patients in ICU and after discharge were not taken into account. In addition, previous studies specifically in France investigating the relation between socioeconomic status and outcomes included different patient populations (e.g. homeless subjects [21]) or used different methods to evaluate deprivation $[21,22]$.

In this context, the present study was designed to assess the impact of deprivation on severity of illness at ICU admission, and on mortality at 3 months after ICU admission.

\section{Methods}

\section{Design and study population}

The IVOIRE study was a prospective, observational, multicentre cohort study in patients admitted to the ICU in 8 participating centres [ 5 university teaching hospitals and 3 mixed ICUs from general (non-academic) hospitals].

All patients aged $\geq 18$ years admitted to the ICU and receiving at least one life support therapy for organ failure (mechanical ventilation, vasopressors or inotropic agents, renal replacement therapy, high flow nasal cannula) were eligible for inclusion. Patients were only included once (i.e. not included a second time in case of re-admission). Patients who were capable of being interviewed, either personally or via a next of kin were included. Patients with major cognitive impairment before admission to the ICU, patients for whom follow-up at 3 months was anticipated to be impossible (e.g. homeless persons), patients with no social security coverage, and patients under legal guardianship or judicial protection were not included.

The study received approval for all participating centres from the local Ethics Committee (Comité de Protection des Personnes Est I) under the number 2013/15 and from the French national agency for the safety of medical products and devices (Agence National de Sécurité des Médicaments et des Produits de Santé, ANSM, approval number 121506B-31). The study was registered with ClinicalTrials.gov under the identifier NCT01907581. All patients and/or their next of kin were informed and consent was documented in the patients' medical records by the investigator.

This study is reported in compliance with the STROBE guidelines [23, 24].

\section{Outcomes}

The primary outcomes were severity at admission, as assessed by the SAPS II score at ICU admission [3], and mortality at 3 months following admission. The SAPS II score was considered as a continuous variable. Secondary outcomes were mortality recorded at 6 and 12 months. For patients who could not be contacted at follow-up, a sequential procedure was followed, namely: telephone contact with the patient, or their family; telephone contact with the general practitioner (GP), or other specialists, then finally, vital status was obtained from the national death registry.

\section{Variables of interest and data collection}

Deprivation status was obtained from interviews with the patients or their next-of-kin during the ICU stay using the EPICES (Evaluation de la Précarité et des Inégalités de santé dans les Centres d'Examen de santé, Evaluation of Deprivation and Inequalities in 
Health Examination Centres) score (Additional file 1). The EPICES score [25] measures social and material deprivation and is based on a multidimensional questionnaire composed of 11 items relating to social conditions, leisure activities and family/social support. This score ranges from 0 to 100 , from the lowest to the highest level of deprivation, but it is mostly used as a dichotomous variable to discriminate deprived and non-deprived patients. Patients with an EPICES score $\geq 30.17$ (lower boundary of the fourth quintile in the validation study) were considered as socially deprived [25-27]. This score, validated in a large French cohort of 197,389 patients, has been shown to be a reliable index to measure social deprivation at an individual level $[25,28]$.

Other data collected included living conditions (own home, retirement home, nursing home), level of education and professional qualification, occupational position, healthcare coverage. We also recorded demographic characteristics, reasons for ICU admission, comorbidities as evaluated by the Charlson index [29], smoking status, level of alcohol intake, Katz's Activities of Daily Living (ADL) [30], variables relating to healthcare utilization (chronic disease, home help, time required to get to the nearest doctor). Severity of disease at baseline was calculated using the Simplified Acute Physiological Score (SAPS) II [3] and Sequential Organ Failure Assessment (SOFA) score [31] at ICU admission. Life support therapy in ICU (mechanical ventilation, vasopressors and/or inotropic agent, renal replacement therapy, high flow nasal cannula), length of ICU and hospital stay were also collected.

Dedicated clinical research assistants collected all data using a standardized electronic case report form. Automatic checks were generated for missing or incoherent data.

We also recorded for each patient the level of social security coverage. France offers universal coverage for all citizens and legal residents, regardless of age or economic situation. Citizens and residents are covered through mandatory health insurance contributions up to approximately 70 to $75 \%$ of costs, and optional private insurance is available for those who want additional coverage (to bring coverage up to $100 \%$ ). Free complementary health insurance is provided for permanent residents of France whose household income falls below a certain threshold. State medical assistance is made available for foreigners whose application for legal residence has not yet been finalized. State medical assistance is provided below a certain level of income, and covers up to $100 \%$ of healthcare costs (100\% of the tariffs determined by the social welfare system).

\section{Sample size calculation}

The mean SAPS II in the ICU of the coordinating centre was 55 (estimates derived from internal statistics). We calculated that a sample size of 1400 participants would be needed to detect an increase in predicted mortality of $10 \%$, which corresponds to a SAPS II score of 60 , and assuming that $20 \%$ of our population [32] would be classified as deprived at an alpha risk of $5 \%$ and power of $80 \%$. This sample size would also enable us to detect OR varying from 1.44 to 1.52 according to deprivation frequency, and assuming expected mortality of $40 \%$ in non-deprived patients.

\section{Statistical analysis}

Continuous variables are expressed as mean \pm standard deviation, or median [Q1, Q3], and categorical variables as number (percentage). Group comparisons were performed using the Chi-square or Fisher's exact test for categorical variables, Student's $t$ test for normally distributed data and the Wilcoxon rank sum test otherwise.

The impact of deprivation status on the severity of illness at ICU admission was assessed by a linear regression model and adjusted for clinically relevant factors (age, sex, level of education, Charlson comorbidity index and ADL score), and centre.

The impact of deprivation status on mortality at 3, 6 and 12 months was studied with a logistic regression model adjusted for clinically relevant prognostic factors (age, SAPS II, ADL score, Charlson comorbidity index) and centre.

Analyses were performed on the complete-case population, and sensitivity analyses were also performed on the imputed population to account for any patients with missing data. Multiple imputations by the chained equation method were performed using 10 imputed datasets. The variables used for imputation were age, sex, SAPS II, Charlson comorbidity index, mortality at 3, 6 and 12 months, the EPICES score, the ADL score, presence of chronic disease, level of education and centre.

The association between deprivation status and life support therapy was also assessed using the Chi-square test, and then by multivariate logistic regression adjusted for SAPS II, septic shock, cardiogenic shock and centre, based on clinical relevance. The association between deprivation status and the destination after discharge (home/ institution/hospital) was assessed by multivariate multinomial logistic regression.

All analyses were performed using SAS version 9.4 (SAS Institute Inc., Cary, NC, USA) with a significance threshold of less than 0.05 in 2-sided tests. 


\section{Results}

From 06 June 2013 to 22 January 2016, a total of 1417 patients were screened for eligibility. Among the 1389 patients who consented to participate in the IVOIRE study and who met the inclusion criteria, 95 patients were excluded from the present analysis due to missing information regarding EPICES score. A flowchart of the study population is shown in Fig. 1. The characteristics of the 1294 patients included in the final analysis are presented in Table 1. Among these, 629 (48.6\%) were classed as deprived. EPICES score ranged from 0 to 29.6 in nondeprived patients (mean $=17.2 \pm 8.8$ ), and from 30.17 to 100 in deprived patients (mean $=47.6 \pm 13.8$ ). Deprived patients differed significantly from non-deprived subjects in terms of sociodemographic characteristics (younger, lower level of education, more often on invalidity or without professional activity), living arrangements (more often living alone) and pre-existing conditions (higher alcohol and tobacco consumption, and dependency). Patients who were deprived more frequently had chronic disease or home help, had greater difficulty paying for their medication and medical exams, and needed more time to get to the nearest GP. Basic French healthcare



coverage and complementary health insurance were also less common in deprived patients, contrary to universal coverage and state medical aid, which were more frequent in these patients. Deprived patients more frequently consulted GPs or specialists in the year prior to their ICU admission, and more frequently had a history of at least one hospital admission in the last year, but less frequently consulted the dentist as compared to nondeprived patients (Additional file 2: Table S1).

\section{Impact of deprivation status on disease severity at admission}

There was no significant difference in the indications for admission according to deprivation (Table 1). The mean SAPS II score at admission was lower in deprived patients compared to non-deprived patients $(50.1 \pm 19.4$ versus $52.3 \pm 17.3$, respectively, $p=0.029)$. This difference was no longer significant by multivariable analysis (adjusted beta $=-1.85$ [95\% CI - 3.86; + 0.165], $p=0.072$ ). Sensitivity analysis including all patients with missing data yielded similar results (Additional file 2: Table S2).

\section{Management in the ICU}

There were no differences in management between deprived and non-deprived patients, except for the use of mechanical ventilation and vasopressors, both significantly less frequent in deprived patients (Additional file 2: Table S3). However, these associations were no longer significant in multivariable logistic regression after adjustment for severity at admission and presence of septic or cardiogenic shock. There was no difference in treatment withholding or withdrawal according to deprivation, regardless of the severity at admission (Additional file 2: Table S3).

\section{Outcomes after discharge from ICU}

There was no significant difference in length of stay in the ICU or in-hospital, or in discharge modalities from the ICU or the hospital according to deprivation status (Table 2). Among patients who were not resident in a nursing home at the time of admission, deprivation was significantly associated with an increased risk of entry into a nursing home at 3 months after discharge $(\mathrm{OR}=2.69 ; 95 \%$ CI $1.40-5.17 ; p=0.004)$ and at 6 months $(\mathrm{OR}=6.06$; 95\% CI 2.23-16.43; $p=0.0004)$, after adjustment for age and dependency level by multivariable multinomial logistic analysis.

The proportion of death was $31.1 \%$ at 3 months, $35.3 \%$ at 6 months and $40.0 \%$ at 12 months, without significant differences between deprived and non-deprived patients, even after adjustment for confounding factors (Table 3; Fig. 2). There was no significant impact of social deprivation on mortality, whatever the score used to assess social 
Table 1 Comparison of deprived and non-deprived patients at admission to the intensive care unit in the IVOIRE cohort $(N=1294)$

\begin{tabular}{|c|c|c|c|c|}
\hline Variable & All $(n=1294)$ & Non-deprived $(n=665)$ & Deprived $(n=629)$ & $p$ \\
\hline \multicolumn{5}{|l|}{ Sociodemographic characteristics } \\
\hline Age & $66.17 \pm 14.93$ & $67.18 \pm 13.95$ & $65.10 \pm 15.84$ & 0.01 \\
\hline Male gender & $805(62.2 \%)$ & $425(63.9 \%)$ & $380(60.4 \%)$ & 0.195 \\
\hline Level of education ${ }^{a, c}$ & & & & $<0.0001$ \\
\hline No educational diplomas/certificates & $249(19.7 \%)$ & $95(14.6 \%)$ & $154(25.0 \%)$ & \\
\hline Primary school certificate and/or some secondary school & $363(28.7 \%)$ & $173(26.6 \%)$ & $190(30.8 \%)$ & \\
\hline Professional certificate & $358(28.3 \%)$ & $193(29.7 \%)$ & $165(26.8 \%)$ & \\
\hline High school diploma or higher & $296(23.4 \%)$ & $189(29.1 \%)$ & $107(17.4 \%)$ & \\
\hline Employment status ${ }^{\mathrm{a}, \mathrm{c}}$ & & & & $<0.0001$ \\
\hline Not working, unemployed or job-seeker, never worked & $143(11.2 \%)$ & $48(7.3 \%)$ & $95(15.3 \%)$ & \\
\hline Employed & $190(14.9 \%)$ & $118(18.0 \%)$ & $72(11.6 \%)$ & \\
\hline Retired & $817(64.1 \%)$ & $456(69.7 \%)$ & $361(58.1 \%)$ & \\
\hline Invalidity & $125(9.8 \%)$ & $32(4.9 \%)$ & $93(15.0 \%)$ & \\
\hline Socioeconomic category ${ }^{\mathrm{a}, \mathrm{c}}$ & & & & $<0.0001$ \\
\hline Farmers & $54(4.2 \%)$ & $34(5.1 \%)$ & $20(3.2 \%)$ & \\
\hline Self-employed/own business & $106(8.2 \%)$ & $59(8.9 \%)$ & $47(7.5 \%)$ & \\
\hline Upper management and liberal professions & $130(10.1 \%)$ & 95 (14.4\%) & $35(5.6 \%)$ & \\
\hline Labourers & $397(30.9 \%)$ & $165(25.0 \%)$ & $232(37.1 \%)$ & \\
\hline Employees/intermediate professions & $500(38.9 \%)$ & $273(41.4 \%)$ & $227(36.3 \%)$ & \\
\hline No profession & $69(5.4 \%)$ & $25(3.8 \%)$ & $44(7.0 \%)$ & \\
\hline Did not wish to disclose & $29(2.3 \%)$ & $9(1.4 \%)$ & $20(3.2 \%)$ & \\
\hline \multicolumn{5}{|l|}{ Living arrangements ${ }^{b}$} \\
\hline Living alone & $372(28.8 \%)$ & $105(15.8 \%)$ & $267(42.4 \%)$ & $<0.0001$ \\
\hline Living with family members & $871(67.3 \%)$ & $556(83.6 \%)$ & $315(50.1 \%)$ & $<0.0001$ \\
\hline In assisted living, long-term care facility or nursing home & $47(3.6 \%)$ & $2(0.3 \%)$ & $45(7.1 \%)$ & $<0.0001$ \\
\hline \multicolumn{5}{|l|}{ Social welfare coverage ${ }^{b}$} \\
\hline Beneficiary of the basic French healthcare system ${ }^{c}$ & $1234(96.4 \%)$ & $642(97.9 \%)$ & $592(94.9 \%)$ & 0.004 \\
\hline Universal healthcare coverage ${ }^{c}$ & $46(3.6 \%)$ & $15(2.3 \%)$ & $31(5.0 \%)$ & 0.010 \\
\hline $\begin{array}{l}\text { Universal coverage + assistance with complementary health } \\
\text { insurance + state medical aid }{ }^{c}\end{array}$ & $47(3.7 \%)$ & $11(1.7 \%)$ & $36(5.8 \%)$ & 0.0001 \\
\hline Complementary health insurance ${ }^{c}$ & $1102(86.2 \%)$ & $612(93.3 \%)$ & $490(78.8 \%)$ & $<0.0001$ \\
\hline \multicolumn{5}{|l|}{ Pre-existing conditions } \\
\hline Alcohol consumption ( $\geq 2$ glasses per day) ${ }^{c}$ & $399(31.7 \%)$ & $179(27.5 \%)$ & $220(36.1 \%)$ & 0.001 \\
\hline Smoking status ${ }^{c}$ & & & & $<0.0001$ \\
\hline Non-smokers & $474(36.8 \%)$ & $272(41.0 \%)$ & $202(32.4 \%)$ & \\
\hline Current smokers & $360(28.0 \%)$ & $144(21.7 \%)$ & $216(34.7 \%)$ & \\
\hline Former smokers & $453(35.2 \%)$ & $248(37.3 \%)$ & $205(32.9 \%)$ & \\
\hline Charlson comorbidity index mean \pm SD & $2.6 \pm 2.5$ & $2.4 \pm 2.4$ & $2.8 \pm 2.6$ & 0.007 \\
\hline Katz ADL score $<3^{c}$ & $88(6.9 \%)$ & $30(4.6 \%)$ & $58(9.3 \%)$ & 0.0009 \\
\hline \multicolumn{5}{|l|}{ Healthcare utilization } \\
\hline Chronic disease $^{c}$ & $839(68.0 \%)$ & $416(64.8 \%)$ & $423(71.4 \%)$ & 0.0123 \\
\hline Home help ${ }^{c}$ & $271(21.4 \%)$ & $121(18.4 \%)$ & $150(24.5 \%)$ & 0.009 \\
\hline Difficulty paying for medication or examinations ${ }^{c}$ & $90(7.2 \%)$ & $16(2.5 \%)$ & $74(12.3 \%)$ & $<0.0001$ \\
\hline Time from home to nearest doctor $\geq 15 \mathrm{~min}^{c}$ & $303(24.4 \%)$ & $131(20.3 \%)$ & $172(28.7 \%)$ & 0.0006 \\
\hline \multicolumn{5}{|l|}{ Severity of illness at admission } \\
\hline$S O F A^{C}$ mean $\pm S D$ & $8.0 \pm 4.0$ & $8.2 \pm 3.8$ & $7.7 \pm 4.2$ & 0.018 \\
\hline Indication for admission to ICU $U^{a, c}$ & & & & 0.194 \\
\hline Cardiac & $188(15.3 \%)$ & $104(16.5 \%)$ & $84(14.0 \%)$ & \\
\hline Gastro-enterology & $63(5.1 \%)$ & 37 (5.9\%) & $26(4.3 \%)$ & \\
\hline
\end{tabular}


Table 1 (continued)

\begin{tabular}{|c|c|c|c|c|}
\hline Variable & All $(n=1294)$ & Non-deprived $(n=665)$ & Deprived $(n=629)$ & $p$ \\
\hline Neurological & $56(4.6 \%)$ & $26(4.1 \%)$ & $30(5.0 \%)$ & \\
\hline Renal & 40 (3.2\%) & $17(2.7 \%)$ & $23(3.8 \%)$ & \\
\hline Respiratory & 392 (31.8\%) & 187 (29.6\%) & 205 (34.1\%) & \\
\hline Sepsis & 325 (26.4\%) & 170 (26.9\%) & 155 (25.8\%) & \\
\hline Trauma & 72 (5.8\%) & $33(5.2 \%)$ & $39(6.5 \%)$ & \\
\hline Other reasons & 96 (7.8\%) & 57 (9.0\%) & $39(6.5 \%)$ & \\
\hline
\end{tabular}

a Percentages may not total 100 because of rounding

b Percentages may not total 100 because more than one answer was possible

c Missing data: level of education $(n=28)$, employment status $(n=19)$, socioeconomic category $(n=9)$, basic healthcare coverage $(n=14)$, universal coverage ( $n=29)$, universal coverage + assistance $(n=31)$, complementary insurance $(n=16)$, alcohol $(n=35)$, smoking $(n=7)$, Katz's ADL score $(n=17)$, long-term disease $(n=60)$, home help $(n=25)$, difficulty paying for medication or examination $(n=48)$, time to nearest doctor $(n=51)$, SOFA( $n=8)$, indication for admission to ICU $(n=62)$

Table 2 Outcomes after discharge from the ICU according to deprivation status in the IVOIRE cohort

\begin{tabular}{|c|c|c|c|}
\hline & $\begin{array}{l}\text { Non-deprived } \\
(n=665)\end{array}$ & $\begin{array}{l}\text { Deprived } \\
(n=629)\end{array}$ & $p$ \\
\hline \multicolumn{4}{|l|}{$\begin{array}{l}\text { Length of stay, days (median } \\
{[\text { [QQR]) }}\end{array}$} \\
\hline ICU & $6[3-11]$ & $5[3-11]$ & $0.557^{b}$ \\
\hline In hospital ${ }^{\mathrm{a}}$ & $17[10-31]$ & 18 [9-35] & $0.576^{b}$ \\
\hline Outcome at ICU discharge, $n(\%)$ & & & $0.557^{c}$ \\
\hline Death & $128(19.2 \%)$ & $118(18.8 \%)$ & \\
\hline Transfer & $530(79.7 \%)$ & $500(79.5 \%)$ & \\
\hline Discharged to home & $7(1.1 \%)$ & $11(1.8 \%)$ & \\
\hline $\begin{array}{l}\text { Outcome at hospital discharge }{ }^{a} \text {, } \\
n(\%)\end{array}$ & & & $0.987^{c}$ \\
\hline Death & $41(7.6 \%)$ & $39(7.6 \%)$ & \\
\hline Transfer & $218(40.6 \%)$ & $205(40.1 \%)$ & \\
\hline Discharged to home & $278(51.8 \%)$ & $267(52.2 \%)$ & \\
\hline
\end{tabular}

a Among patients alive at ICU discharge $(n=1048)$

${ }^{\mathrm{b}}$ Wilcoxon rank test

c Chi-square test

vulnerability. Sensitivity analysis including all patients with missing data yielded similar results (Additional file 2: Table S4).

\section{Discussion}

This is one of the first studies to be performed in France investigating the impact of deprivation at individual level on severity at admission and mortality. In France, there exist substantial inequalities in healthcare [33, 34], and the healthcare system is profoundly different to the systems used elsewhere in Europe, especially in AngloSaxon countries $[35,36]$. The French insurance system provides a basic level of medical coverage to all citizens, and $100 \%$ coverage for serious or chronic diseases. Our study shows that among all patients admitted to the ICU, just under $50 \%$ were deprived, and these patients had similarly severe disease at admission, as assessed by SAPS II and SOFA scores, and no significant difference in mortality at 3 months according to deprivation status. We also observed that deprived patients who were living at home at the time of admission had a higher risk of entry into a nursing home at 3 and 6 months after discharge from the ICU by multivariable analysis. This could be explained by the fact that deprived patients had a higher level of dependence at admission, as assessed by ADLs, and more comorbidities, as assessed by the Charlson index.

The rate of deprived patients admitted to the ICU in our study is difficult to compare with other literature

Table 3 Impact of deprivation on mortality at 3, 6 and 12 months following ICU admission

\begin{tabular}{|c|c|c|c|c|c|c|}
\hline & \multicolumn{2}{|l|}{3 months } & \multicolumn{2}{|l|}{6 months } & \multicolumn{2}{|l|}{12 months } \\
\hline & Non-deprived & Deprived & Non-deprived & Deprived & Non-deprived & Deprived \\
\hline Mortality & $30.5 \%$ & $31.6 \%$ & $35.3 \%$ & $35.3 \%$ & $39.1 \%$ & $40.9 \%$ \\
\hline $\begin{array}{l}\text { Crude OR }[95 \% \mathrm{Cl}] \\
(n=1294)\end{array}$ & 1 & $1.05[0.83 ; 1.33]$ & 1 & $1.00[0.80-1.25]$ & 1 & $1.07[0.86 ; 1.34]$ \\
\hline $\begin{array}{l}\text { Adjusted OR }[95 \% \mathrm{Cl}] \\
(n=1277)\end{array}$ & 1 & $1.04[0.79-1.37]$ & 1 & $0.97[0.75-1.27]$ & 1 & $1.06[0.82-1.37]$ \\
\hline
\end{tabular}

Cl confidence interval

a Multivariate analysis was adjusted for age, SAPS II score, Katz's ADL, Charlson comorbidity index and centre 


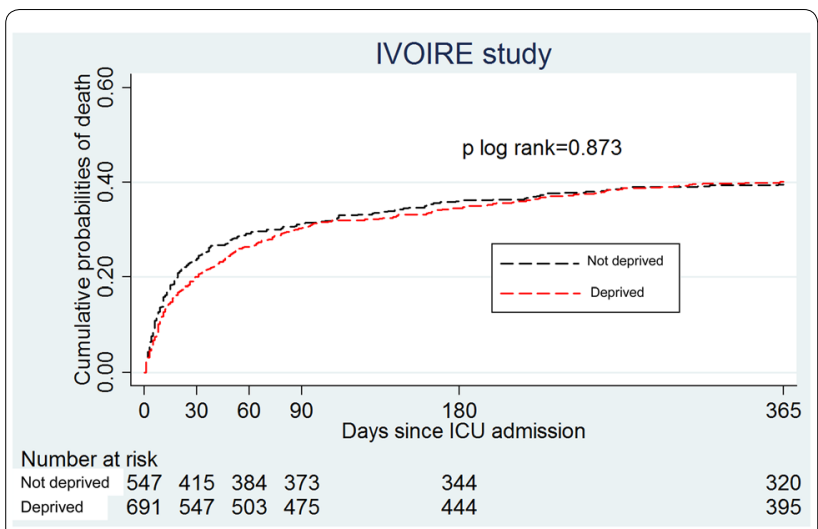

Fig. 2 Cumulative probabilities of death within 365 days following ICU admission. ICU intensive care unit

reports, because we used a different definition to classify patients as deprived than previous reports $[6-8,17]$. The definition of social deprivation is complex, because it is not a binary state but rather a dynamic concept with different degrees of vulnerability and comprising different dimensions. In our study, we chose to use the EPICES score, which is increasingly implemented in France to evaluate deprivation. Previous studies focused more on healthcare inequalities and socioeconomic factors (including psycho-social and material aspects) that could influence health states in the population, to which may also be added behavioural determinants such as alcohol consumption, smoking, dietary habits, or physical activity [9, 37-41]. A previous study by Bigé et al. among homeless people in France reported that $50 \%$ of patients had no health insurance, $56 \%$ had no financial resources, and $91 \%$ were socially isolated, but that they had the same prognosis overall as housed patients [21]. Our findings are in line with these reports in terms of impact of socioeconomic status on mortality. Conversely, the rate of deprivation observed in our study (48.6\%) is higher than that reported in other studies $(26 \%$ in the study by Bein et al. [17] and 33\% in the study by Bastian et al. [22]). These differences may be explained by the fact that these studies included different patient populations, and also used other indices of socioeconomic status. The EPICES score is a multidimensional instrument that encompasses several dimensions and therefore, may be more sensitive.

There are disparities in the reported risk factors for deprivation, and other reports found a much stronger impact of deprivation on prognosis than our study [4244]. Some authors have previously reported that deprivation was associated with increased severity of patients at admission to the ICU $[17,20,45]$, whereas we observed that deprivation was not associated with severity of illness, in line with the findings of others [19]. In deprived patients, we observed a higher level of dependency and more comorbidities at admission, likely explaining why they were admitted to the ICU earlier, and thus, earlier in the course of the disease. Another possible explanation is that deprived patients more frequently consult their GP and specialists, and are therefore more rapidly oriented towards hospitalization as soon as a health problem arises.

Accordingly, they may be more inclined to be hospitalized, especially those with chronic diseases who have $100 \%$ healthcare coverage, than non-deprived patients $[42,46]$. This phenomenon has previously been observed in a study from the province of Nova Scotia in Canada, which reported that universal healthcare led to significantly greater use of family physician and hospital services among individuals with a lower socioeconomic background [46]. Conversely, we cannot rule out the possibility that the deprived population comprises both patients who are frequent users of the healthcare system, and patients who are far from the healthcare system. This latter group might tend to wait longer before seeking medical help, especially those who live alone [47], likely also with more limited access to intensive care facilities [48, 49]. This is particularly true in areas where there are limited opportunities for intensive care. The combination of insufficient social support, and poorer basic health state with fewer physiological reserves, may lead these patients to be hospitalized from the outset, even though their overall state may be less serious. Few studies to date have investigated the impact of deprivation on mediumterm mortality after a stay in the ICU. A recent European, observational cohort study found no association between socioeconomic status and 1-year all-cause mortality after discharge from the ICU [50]. However, in this study, socioeconomic status was not measured at individual level, but was assessed using a composite index that aggregates data based on the zip code of residence to calculate an overall deprivation index. Furthermore, patients who died in the ICU and those with no healthcare coverage were excluded from the study, such that the study population was more highly selected than in the IVOIRE cohort.

We observed that deprived patients had a similar mortality rate at 3 and 6 months, and 1 year as nondeprived patients. The literature can provide clues that might explain this finding. A potential explanation is that patients were managed optimally in the ICU and in post-intensive care, regardless of their deprivation status. The role of allied health professionals such as social workers and rehabilitation services after discharge, as well as home-help organizations likely buffered the 
potentially deleterious effects of the ICU stay in terms of mortality in the most deprived patients. It is also possible that the frailest and perhaps most deprived patients were not admitted to the ICU because of unfavourable prognosis.

\section{Study limitations}

This study presents some limitations that deserve to be taken into account. Firstly, a small proportion of patients could not be analysed because they were missing data for the EPICES score. However, sensitivity analysis showed that this missing data did not affect the overall results. Secondly, the scale used to evaluate deprivation is validated in France, but the healthcare system in France is quite specific, and therefore results likely can only be extrapolated to countries with health insurance systems of the same type. In addition, we cannot exclude possible interactions between the components of deprivation, or an influence of other unmeasured confounders on deprivation. Indeed, the EPICES score is likely a better reflection of overall vulnerability than actual deprivation in social terms. Thirdly, in the absence of data regarding our target population at the time this study was designed, we hypothesized that $20 \%$ of the population would be deprived. In fact, almost $50 \%$ were deprived as assessed by the EPICES score. This actually reinforces our findings, by increasing the statistical power of the study. Fourth, the proportion of screened patients who were actually included in the study was low. This probably stems from reasons relating to different durations of participation between centres, different department size and patient profiles, and human resources issues. Indeed, the commitment of some participating centres may have waned or varied between centres, due to the fact that not all centres have dedicated study personnel (such as clinical research assistants, study nurses, etc.). Finally, there may have been other factors that might influence mortality after ICU discharge that were not taken into account, including (but not limited to) rehabilitation, assistance for deprivation, etc.

\section{Conclusion}

Deprivation is frequent in patients admitted to the ICU and is not associated with severity of disease at admission. Although there was no significant difference in mortality at 3 months and 1 year between deprived and non-deprived patients, socially deprived patients more frequently enter a nursing home within the months following ICU discharge. The findings of this study warrant confirmation on a wider scale, with particular focus on the social support provided for deprived patients after discharge from the ICU.

\section{Supplementary information}

Supplementary information accompanies this paper at https://doi. org/10.1186/s13613-020-0637-1.

Additional file 1. EPICES Score.

Additional file 2: Table S1. Healthcare utilization according to deprivation status. Table S2. Impact of deprivation on SAPS II: $\beta$ estimates from multivariable linear regression model (1) after multiple imputation procedure and (2) after analysis on complete cases. Table S3. Comparison of management in ICU according to deprivation status. Table S4. Impact of deprivation on mortality: $\beta$ estimates from multivariable logistic regression model (1) after multiple imputation procedure and (2) after analysis on complete cases.

\section{Acknowledgements}

The authors thank participating ICUs; clinical research assistants for data entry; Marie-Laure Humbert Asensio and Emilie Galizzi, project leader (INSERM CIC1432 Epidémiologie Clinique, Dijon, France), Sandrine Daniel, datamanager (INSERM CIC1432 Epidémiologie Clinique, Dijon, France); and Fiona Ecarnot, PhD (EA3920, University Hospital Besancon, France) for translation and critical revision.

Members of the IVOIRE Study group: Nancy Brabois: Bruno Lévy, Service de Réanimation Médicale, CHRU de Nancy, France; Nancy central: Jérémie Lemarié, Service de Médecine Intensive-Réanimation, CHRU de Nancy, France; Metz: Cyril Cadoz, Service de Réanimation Médicale, CH de Metz, France; Dieppe: Antoine Marchalot, Service de Médecine Intensive Réanimation, $\mathrm{CH}$ de Dieppe, France; Strasbourg: Alexandra Monnier, Service de Réanimation Médicale, and Yannick Rabouel, Service de Réanimation Médicale, NHC de Strasbourg, France.

\section{Authors' contributions}

Conception and design: JPQ, AD, NMB, JPR, CB. Data collection: JPQ, JH, GL, $A D, N M B, E K, P E B, G L, A L, P A, C B, J P R, P P, R C J, H M, H D, F M$. Data analysis and interpretation: JPQ, NMB, EK, JPR, CB, IF. Drafting of the manuscript: JPQ, NMB, EK, CB, IF. Critical revision for intellectual content: all. Final approval of manuscript for submission: all. All authors read and approved the final manuscript.

\section{Funding}

Supported by a grant from the Programme Hospitalier de Recherche Clinique Interrégional National, 2013 (A00095-40), funded by the French Ministry of Health and by a French Government grant managed by the French National Research Agency (ANR) as part of the "Investissements d'Avenir" program (reference ANR-11-LABX-0021-01-LipSTIC Labex). The funding bodies had no involvement in the design of the study, collection, analysis, and interpretation of data, or in writing the manuscript.

\section{Availability of data and materials}

The datasets used and/or analysed during the current study are available from the corresponding author on reasonable request.

\section{Ethics approval and consent to participate}

The study received approval for all participating centres from the local Ethics Committee (Comité de Protection des Personnes Est I) under the number 2013/15 and from the French national agency for the safety of medical products and devices (Agence National de Sécurité des Médicaments et des Produits de Santé, ANSM, approval number 121506B-31). All patients and/or their next of kin were informed and consent was documented in the patients' medical records by the investigator.

\section{Consent for publication}

Not applicable.

\section{Competing interests}

The authors declare that they have no competing interests. 


\begin{abstract}
Author details
1 Service de Médecine Intensive-Réanimation, CHU Dijon Bourgogne, 14 rue Paul Gaffarel, B.P 77908, 21079 Dijon Cedex, France. ${ }^{2}$ INSERM, U1231, Equipe Lipness, Dijon, France. ${ }^{3}$ LipSTIC LabEx, Fondation de coopération scientifique Bourgogne-Franche-Comté, Dijon, France. ${ }^{4}$ INSERM, CIC 1432, Module Epidémiologie Clinique, Dijon, France. ${ }^{5}$ Hôpitaux universitaires de Strasbourg, Service de Réanimation, Nouvel Hôpital Civil, Strasbourg, France. ${ }^{6}$ Université de Strasbourg (UNISTRA), Faculté de Médecine, Strasbourg, France. ${ }^{7}$ Service de Réanimation Médicale, $\mathrm{CHU}$ de Besançon, Besançon, France. ${ }^{8}$ DRCI, USMR, CHU Dijon Bourgogne, Dijon, France. ${ }^{9}$ Service de Médecine Intensive-Réanimation, CHRU Central, Nancy, France. ${ }^{10}$ Service de Réanimation Médicale, CH de Metz, Metz, France. ${ }^{11}$ Service de Réanimation Polyvalente, $\mathrm{CH}$ de la HauteSaône, Vesoul, France. ${ }^{12}$ Service de Médecine Intensive Réanimation, $\mathrm{CH}$ de Dieppe, Dieppe, France. ${ }^{13}$ Service de Réanimation Médicale, CHRU Brabois, Nancy, France. ${ }^{14}$ Service de Médecine Interne et Maladies Systémiques, CHU Dijon Bourgogne, Dijon, France. ${ }^{15}$ INSERM (French National Institute of Health and Medical Research), UMR 1260, Regenerative Nanomedicine (RNM), FMTS, Strasbourg, France.
\end{abstract}

Received: 22 June 2019 Accepted: 2 February 2020 Published online: 11 February 2020

\section{References}

1. Fernandez R, Serrano JM, Umaran I, Abizanda R, Carrillo A, Lopez-Pueyo MJ, et al. Ward mortality after ICU discharge: a multicenter validation of the Sabadell score. Intensive Care Med. 2010;36:1196-201.

2. Angus DC, Carlet J. Surviving intensive care: a report from the 2002 Brussels Roundtable. Intensive Care Med. 2003;29:368-77.

3. Le Gall JR, Lemeshow S, Saulnier F. A new Simplified Acute Physiology Score (SAPS II) based on a European/North American multicenter study. JAMA. 1993;270:2957-63.

4. Knaus WA, Draper EA, Wagner DP, Zimmerman JE. APACHE II: a severity of disease classification system. Crit Care Med. 1985;13:818-29.

5. Vincent JL, Moreno R, Takala J, Willatts S, De Mendonca A, Bruining $\mathrm{H}$, et al. The SOFA (Sepsis-related Organ Failure Assessment) score to describe organ dysfunction/failure. On behalf of the Working Group on Sepsis-Related Problems of the European Society of Intensive Care Medicine. Intensive Care Med. 1996;22:707-10.

6. Moor I, Spallek J, Richter M. Explaining socioeconomic inequalities in selfrated health: a systematic review of the relative contribution of material, psychosocial and behavioural factors. J Epidemiol Community Health. 2017;71:565-75.

7. Oude Groeniger J, Kamphuis CB, Mackenbach JP, van Lenthe FJ. Repeatedly measured material and behavioral factors changed the explanation of socioeconomic inequalities in all-cause mortality. J Clin Epidemiol. 2017:91:137-45.

8. Hardin SR. Vulnerability of older patients in critical care. Crit Care Nurse. 2015;35:55-61.

9. Mackenbach JP, Stirbu I, Roskam AJ, Schaap MM, Menvielle G, Leinsalu M, et al. Socioeconomic inequalities in health in 22 European countries. N Engl J Med. 2008;358:2468-81.

10. Cox AM, McKevitt C, Rudd AG, Wolfe CD. Socioeconomic status and stroke. Lancet Neurol. 2006:5:181-8.

11. Fried LP, Kronmal RA, Newman AB, Bild DE, Mittelmark MB, Polak JF, et al. Risk factors for 5-year mortality in older adults: the Cardiovascular Health Study. JAMA. 1998;279:585-92.

12. Haider AH, Chang DC, Efron DT, Haut ER, Crandall M, Cornwell EE 3rd. Race and insurance status as risk factors for trauma mortality. Arch Surg. 2008;143:945-9.

13. Schwartz KL, Crossley-May H, Vigneau FD, Brown K, Banerjee M. Race, socioeconomic status and stage at diagnosis for five common malignancies. Cancer Causes Control. 2003;14:761-6.

14. Faggiano F, Partanen T, Kogevinas M, Boffetta P. Socioeconomic differences in cancer incidence and mortality. IARC Sci Publ. 1997;138:65-176.

15. Hodgson CL, Udy AA, Bailey M, Barrett J, Bellomo R, Bucknall T, et al. The impact of disability in survivors of critical illness. Intensive Care Med. 2017:43:992-1001.
16. Welch CA, Harrison DA, Hutchings A, Rowan K. The association between deprivation and hospital mortality for admissions to critical care units in England. J Crit Care. 2010;25:382-90.

17. Bein T, Hackner K, Zou T, Schultes S, Bosch T, Schlitt HJ, et al. Socioeconomic status, severity of disease and level of family members' care in adult surgical intensive care patients: the prospective ECSSTASI study. Intensive Care Med. 2012:38:612-9.

18. Griffiths J, Hatch RA, Bishop J, Morgan K, Jenkinson C, Cuthbertson BH, et al. An exploration of social and economic outcome and associated health-related quality of life after critical illness in general intensive care unit survivors: a 12-month follow-up study. Crit Care. 2013;17:R100.

19. Findlay $J Y$, Plenderleith $J L$, Schroeder DR. Influence of social deprivation on intensive care outcome. Intensive Care Med. 2000;26:929-33.

20. Storm L, Schnegelsberg A, Mackenhauer J, Andersen LW, Jessen MK, Kirkegaard $\mathrm{H}$. Socioeconomic status and risk of intensive care unit admission with sepsis. Acta Anaesthesiol Scand. 2018;62:983-92.

21. Bige N, Hejblum G, Baudel JL, Carron A, Chevalier S, Pichereau C, et al. Homeless Patients in the ICU: an Observational Propensity-Matched Cohort Study. Crit Care Med. 2015;43:1246-54.

22. Bastian K, Hollinger A, Mebazaa A, Azoulay E, Feliot E, Chevreul K, et al. Association of social deprivation with 1-year outcome of ICU survivors: results from the FROG-ICU study. Intensive Care Med. 2018;44:2025-37.

23. von Elm E, Altman DG, Egger M, Pocock SJ, Gotzsche PC, Vandenbroucke $J$, et al. The Strengthening the Reporting of Observational Studies in Epidemiology (STROBE) statement: guidelines for reporting observational studies. Int J Surg. 2014;12:1495-9.

24. Vandenbroucke JP, von Elm E, Altman DG, Gotzsche PC, Mulrow CD, Pocock SJ, et al. Strengthening the Reporting of Observational Studies in Epidemiology (STROBE): explanation and elaboration. PLoS Med. 2007;4:e297.

25. Labbe E, Blanquet M, Gerbaud L, Poirier G, Sass C, Vendittelli F, et al. A new reliable index to measure individual deprivation: the EPICES score. Eur J Public Health. 2015:25:604-9.

26. Centre technique d'appui et de formation des centres d'examens de santé. [The EPICES score: indicator of precarity in healthcare centres of the social security. Study report]. Saint Etienne; 2005. http://www.depar tement-information-medicale.com/wp-content/uploads/2009/05/ re_precarite.pdf. Accessed 12 Oct 2019.

27. Bihan H, Ramentol M, Fysekidis M, Auclair C, Gerbaud L, Desbiez F, et al. Screening for deprivation using the EPICES score: a tool for detecting patients at high risk of diabetic complications and poor quality of life. Diabetes Metab. 2012;38:82-5.

28. Sass C, Gueguen R, Moulin JJ, Abric L, Dauphinot V, Dupre C, et al. Comparison of the individual deprivation index of the French Health Examination Centres and the administrative definition of deprivation. Sante publique. 2006;18:513-22.

29. Charlson ME, Pompei P, Ales KL, Mackenzie CR. A new method of classifying prognostic comorbidity in longitudinal studies: development and validation. J Chronic Dis. 1987;40:373-83.

30. Katz S, Ford AB, Moskowitz RW, Jackson BA, Jaffe MW. Studies of illness in the aged. The index of ADL: a standardized measure of biological and psychosocial function. JAMA. 1963;185:914-9.

31. Ferreira FL, Bota DP, Bross A, Melot C, Vincent JL. Serial evaluation of the SOFA score to predict outcome in critically ill patients. JAMA. 2001;286:1754-8.

32. Pascal J, Abbey-Huguenin H, Agard C, Asseray N, Billaud E, Baron D, et al. Development of a tool for the identification of socially vulnerable hospital patients. Presse Med. 2004;33:710-5.

33. Faure E, Rican S. Gender inequalities and health promotion at the local scale. The case of Gennevilliers (Paris region). Sante publique. 2018;30:617-21.

34. Gusmano MK, Weisz D, Rodwin VG, Lang J, Qian M, Bocquier A, et al. Disparities in access to health care in three French regions. Health Policy. 2014;114:31-40.

35. Li C, Hedblad B, Rosvall M, Buchwald F, Khan FA, Engstrom G. Stroke incidence, recurrence, and case-fatality in relation to socioeconomic position: a population-based study of middle-aged Swedish men and women. Stroke. 2008;39:2191-6.

36. Menvielle G, Chastang JF, Luce D, Leclerc A. Changing social disparities and mortality in France (1968-1996): cause of death analysis by educational level. Rev Epidemiol Sante Publique. 2007;55:97-105. 
37. van Lenthe FJ, Kamphuis CB, Beenackers MA, Jansen T, Looman CW, Nusselder WJ, et al. Cohort profile: understanding socioeconomic inequalities in health and health behaviours: the GLOBE study. Int J Epidemiol. 2014;43:721-30

38. Granstrom F, Molarius A, Garvin P, Elo S, Feldman I, Kristenson M. Exploring trends in and determinants of educational inequalities in self-rated health. Scand J Public Health. 2015;43:677-86.

39. Kershaw KN, Droomers M, Robinson WR, Carnethon MR, Daviglus ML, Monique Verschuren WM. Quantifying the contributions of behavioral and biological risk factors to socioeconomic disparities in coronary heart disease incidence: the MORGEN study. Eur J Epidemiol. 2013;28:807-14

40. Hoven H, Siegrist J. Work characteristics, socioeconomic position and health: a systematic review of mediation and moderation effects in prospective studies. Occup Environ Med. 2013;70:663-9.

41. Gebremariam MK, Altenburg TM, Lakerveld J, Andersen LF, Stronks K, Chinapaw MJ, et al. Associations between socioeconomic position and correlates of sedentary behaviour among youth: a systematic review. Obes Rev. 2015;16:988-1000.

42. Jones L, Bates G, McCoy E, Bellis MA. Relationship between alcoholattributable disease and socioeconomic status, and the role of alcoho consumption in this relationship: a systematic review and meta-analysis. BMC Public Health. 2015;15:400.

43. Casetta B, Videla AJ, Bardach A, Morello P, Soto N, Lee K, et al. Association between cigarette smoking prevalence and income level: a systematic review and meta-analysis. Nicotine Tob Res. 2017;19:1401-7.

44. Katikireddi SV, Whitley E, Lewsey J, Gray L, Leyland AH. Socioeconomic status as an effect modifier of alcohol consumption and harm: analysis of linked cohort data. Lancet Public Health. 2017;2:e267-76.
45. Latour J, Lopez V, Rodriguez M, Nolasco A, Alvarez-Dardet C. Inequalities in health in intensive care patients. J Clin Epidemiol. 1991;44:889-94.

46. Veugelers PJ, Yip AM. Socioeconomic disparities in health care use: does universal coverage reduce inequalities in health? J Epidemiol Community Health. 2003;57:424-8.

47. Floud S, Balkwill A, Canoy D, Wright FL, Reeves GK, Green J, et al. Marital status and ischemic heart disease incidence and mortality in women: a large prospective study. BMC Med. 2014;12:42.

48. Erickson SE, Vasilevskis EE, Kuzniewicz MW, Cason BA, Lane RK, Dean ML, et al. The effect of race and ethnicity on outcomes among patients in the intensive care unit: a comprehensive study involving socioeconomic status and resuscitation preferences. Crit Care Med. 2011;39:429-35.

49. Muni S, Engelberg RA, Treece PD, Dotolo D, Curtis JR. The influence of race/ethnicity and socioeconomic status on end-of-life care in the ICU. Chest. 2011;139:1025-33.

50. Gayat E, Cariou A, Deye N, Vieillard-Baron A, Jaber S, Damoisel C, et al. Determinants of long-term outcome in ICU survivors: results from the FROG-ICU study. Crit Care. 2018;22:8.

\section{Publisher's Note}

Springer Nature remains neutral with regard to jurisdictional claims in published maps and institutional affiliations.

\section{Submit your manuscript to a SpringerOpen ${ }^{\circ}$ journal and benefit from:}

- Convenient online submission

$\checkmark$ Rigorous peer review

- Open access: articles freely available online

- High visibility within the field

- Retaining the copyright to your article

Submit your next manuscript at $\boldsymbol{\nabla}$ springeropen.com 